\title{
TYROSINE HYDROXYLASE ACTIVITY DECREASES WITH INDUCTION OF CHOLINERGIC PROPERTIES IN CULTURED SYMPATHETIC NEURONS ${ }^{1}$
}

\author{
EVE WOLINSKY ${ }^{2}$ AND PAUL H. PATTERSON
}

Department of Neurobiology, Harvard Medical School, Boston, Massachusetts 02115

Received December 13, 1982; Revised February 25, 1983; Accepted March 1, 1983

\begin{abstract}
Establishment of transmitter phenotype is an essential step in neuronal development. Studies on ral sympathelic neurons both in vivo and in vitro have provided evidence that mature cholinergic sympathetic neurons arise from previously noradrenergic neurons. Cultured rat superior cervical ganglion neurons can be influenced by their environment to remain noradrenergic, to acquire dual transmitter function, or to become predominantly cholinergic. Several other neuronal traits, such as a variety of surface molecules and released proteins, change simultaneously with levels of catecholamine and acetylcholine production, suggesting that various components of transmitter phenotype are regulated in concert. In this report, tyrosine hydroxylase levels are compared in neurons cultured under noradrenergic, dual function, or cholinergic conditions. Both enzyme activity in cell extracts and immunocytochemical staining were measured. These methods showed significantly less tyrosine hydroxylase enzyme activity and immunoreactive material in cholinergic cultures compared to noradrenergic and dual function cultures. These data support the interpretation that a switch in transmitter status from noradrenergic to cholinergic has occurred. This interpretation contrasts with that of Iacovitti et al. (Iacovitti, L., T. H. Joh, D. H. Park, and R. P. Bunge (1981) J. Neurosci. 1: 685-690), who conducted their experiments under critically different culture conditions.
\end{abstract}

The transmitter phenotype of a neuron is comprised of numerous differentiated properties, including the enzymes necessary for transmitter synthesis and breakdown, the vesicles for storage, and in some cases, the membrane sites for reuptake. One interesting question concerning control of gene expression is whether the various elements of a phenotype are controlled coordinately during development. For example, some cells of the sympathoadrenal lineage, adrenal chromaffin cells, acquire three characteristic enzymes of the catecholamine (CA) biosynthetic pathway at approximately the same time in embryogenesis (Cochard et al., 1978, 1979; Teitelman et al., 1979). However, in other cell types of this lineage, only one or two of the enzymes may develop. Neuronal differentiation can involve not only acquisition

\footnotetext{
${ }^{1}$ This work was supported by grants from the National Institute of Neurological and Communicative Disorders and Stroke. E. W. is a predoctoral trainee of the National Institute of General Medical Sciences and P. H. P. is a Rita Allen Foundation Scholar and a McKnight Foundation Neuroscience Development Awardee. We wish to thank Doreen McDowell, Geraldine Spencer, Allison Doupe, and Shirley Wilson for assistance with the cell cultures and with the preparation of the manuscript. We also thank Tom Jessell for advice on photography. Antiserum against tyrosine hydroxylase was a gift from J. Thibeault.

" To whom correspondence should be addressed.
}

of particular elements of a phenotype, but their loss as well. For example, some autonomic noradrenergic neurons change their transmitter phenotype during ontogenesis. In developing sweat glands of the rat footpad, the noradrenergic properties of the early innervation are gradually reduced, as the innervation becomes cholinergic. As these axons become positive for the acetylcholinesterase cytochemical reaction, endogeneous CA stores are lost and immunocytochemical staining for tyrosine hydroxylase (TH) and dopamine $\beta$-hydroxylase become greatly reduced (Landis and Keefe, 1980, 1983b; Siegel et al. 1982). Although the mature cholinergic axons lose their endogenous CA stores, they maintain to some extent the distinctive noradrenergic capability to take up exogenous CA.

These findings on the differential loss of adrenergic properties with attainment of cholinergic development in vivo are in qualitative agreement with earlier studies on the cholinergic differentiation of sympathetic neurons in vitro. Varying the culture environment of neonatal rat superior cervical ganglion neurons can produce a spectrum of transmitter types ranging from nearly purely adrenergic to dual function, to predominantly cholinergic neurons (Reichardt and Patterson, 1977; Potter et al., 1981). Under culture conditions favoring expression of 
cholinergic functions, development of certain noradrenergic properties is inhibited. These include accumulation of endogenous CA stores (Landis, 1976, 1980; Johnson et al., 1976, 1980), the ability to synthesize and store CA (Patterson et al., 1975; Patterson and Chun 1977a, b; Schaffner and Danicls, 1982) and the presence of an isozyme of monoamine oxidase associated with noradrenergic neurons (Pintar et al., 1981). However, such cholinergic neurons still retain the ability to take up exogenous CA via the high affinity uptake I system (Reichardt and Patterson 1977; Wakshull et al., 1978; Landis, 1980), as do the mature cholinergic sympathetic axons of the rat footpad. The degrce of suppression of development of noradrenergic properties is dependent on the length of time and the concentration of conditioned medium factor applied (Johnson et al., 1976; Patterson and Chun, 1977a, b; Landis, 1980). When neurons are only weakly cholinergically induced, individual cells retain the ability to secrete both transmitters indefinitely (Furshpan et al., 1976; Potter et al., 1981).

Recent reports have confirmed and extended the previous description of the dual function state. Cultured neurons which have formed cholinergic synapses can exhibit immunocytochemical staining for TH (Higgins et al., 1981) and TH and choline acetyltransferase enzyme activities can increase in parallel in culture (Iacovitti et al., 1981). However, these authors hypothesize that the inhibition of development of CA synthesis and accumulation and the loss of CA stores in neurons grown under strongly cholinergic conditions are not caused by failure of $\mathrm{CA}$ synthetic enzymes to develop, but rather are caused by acetylcholine (ACh) competing with $\mathrm{CA}$ for storage within the same vesicle population (Johnson and Higgins, 1981). This model predicts that CA synthesis, but not storage, would increase steadily with time in culture in parallel with ACh production. In the present report, however, it is shown that there are significant differences in both TH specific activity and TH immunocytochemical staining in neurons grown under strongly cholinergic versus adrenergic conditions, that this difference depends on the strength of the cholinergic induction, and that the difference in $\mathrm{TH}$ activity parallels earlier data on CA synthesis and accumulation by living neurons.

\section{Materials and Methods}

Cell culture. Neuronal cultures were prepared essentially by the method of Hawrol and Patterson (1979), except that cell dissociation was accomplished enzymatically rather than mechanically. Superior cervical ganglia of newborn rats were dissected, cleaned of extraneous tissue, and then incubated at $37^{\circ} \mathrm{C}$ for 1 to $2 \mathrm{hr}$ in a solution of proteolytic enzymes. This enzyme solution consisted of $5 \mathrm{mg} / \mathrm{ml}$ of dispase (neutral protease from Bacillus polymyxa Grade II, Boehringer-Mannheim) and $1 \mathrm{mg} / \mathrm{ml}$ of collagenase (126 units/mg; Worthington) in $\mathrm{Ca}^{2+}, \mathrm{Mg}^{2+}$-free Hanks' balanced salt solution supplemented with glucose, antibiotics, and glutamine, as described for plating medium (Hawrot and Patterson, 1979). For each 10 ganglia, $1 \mathrm{ml}$ of enzyme solution was used. Dissociation to single cells was effected by 4 to 6 passes through an 18 gauge, 1-inch syringe needle. The resulting suspension was washed three times by low speed centrifugation in plating medium (without $\mathrm{NaHCO}_{3}$ ) to remove the dispase and collagenase and then was restored to an appropriate volume with plating medium. Since large numbers of non-neuronal cells are released during enzymatic dissociation, the suspension was plated directly into growth medium containing $10^{-5}$ M cytosine-1- $\beta$-D-arabinofuranoside (Sigma Chemical Co.) A 1-week exposure to this antimetabolite virtually eliminated non-neuronal cells from the cultures. Growth medium consisted of carbonate-buffered L15 (Flow Labs) supplemented with glucose, antibiotics, glutamine, and fresh vitamins (Hawrot and Patterson, 1979), $1 \mu \mathrm{g} / \mathrm{ml}$ of nerve growth factor prepared by the method of Bocchini and Angeletti (1969), and 5\% adult rat serum. Depolarizing growth medium for the production of noradrenergic cultures contained $20 \mathrm{~mm} \mathrm{KCl}$ exchanged for an equal amount of $\mathrm{NaCl}$. Cultures were used for experiments between 3 and 4 weeks in vitro.

Heart cell-conditioned medium. Serum-free heart cellconditioned medium was prepared according to the method of Fukada (1980) and was partially purified and concentrated 10 -fold by ammonium sulfate precipitation as described by Weber (1981). The concentrate was mixed with equal parts of growth medium containing a double supplement of glucose, glutamine, antibiotics, fresh vitamins, nerve growth factor, and rat serum.

TH assay. TH was assayed by the method of Hendry and Iversen (1971) with modifications. Approximately 3000 neurons were homogenized on ice in ground glass microhomogenizers (200 $\mu$ l capacity) in $0.8 \mathrm{M}$ sodium phosphate buffer at $\mathrm{pH} 6$ with $0.05 \%$ Triton X-100. A total volume of $10 \mu \mathrm{l}$ of neuronal extract and extraction buffer was added to an equal volume of assay cocktail. The final concentrations of reagents in this mixture were: $0.0015 \%$ brocrescine, an inhibitor of DOPA decarboxylase (gift of American Cyanamid Co.), $0.15 \mathrm{M} \beta$-mercaptoethanol (Sigma), 1.4 nM 6,7-dimethyl-5,6,7,8-tetrahydropterine hydrochloride (Calbiochem), $25 \mu \mathrm{M}$ L-tyrosine (Sigma), $1 \mathrm{~mm} \mathrm{Fe}\left(\mathrm{NH}_{4}\right)_{2}\left(\mathrm{SO}_{4}\right)_{2} \cdot 6 \mathrm{H}_{2} \mathrm{O}$, and $0.025 \%$ Triton $\mathrm{X}-100$. The reaction was initiated by addition of $5 \mu \mathrm{l}$ of pretrealed, tritium-labeled tyrosine. $\mathrm{L}-\left[\right.$ ring- $\left.2,6{ }^{3} \mathrm{H}\right]$ tyrosine (New England Nuclear (NEN)) of specific activity $30 \mathrm{Ci} / \mathrm{mmol}$ at a concentration of $1 \mathrm{mCi} / \mathrm{ml}$ in $0.01 \mathrm{~N} \mathrm{HCl}$ was neutralized with $0.1 \mathrm{~N} \mathrm{NaOH}$ and incubated with 2 to $3 \mathrm{mg}$ of alumina (WN3; Sigma) at room temperature for $1 \mathrm{hr}$. The reaction was linear for up to at least $10 \mu \mathrm{l}$ of neuronal extract for $15 \mathrm{~min}$. Assays were routinely terminated after $10 \mathrm{~min}$ by addition of ice-cold $0.4 \mathrm{~N}$ perchloroacetic acid containing $8 \mu \mathrm{g} / \mathrm{ml}$ of L-DOPA (Sigma). Alumina pencil columns were used to collect $\left[{ }^{3} \mathrm{H}\right]$ DOPA as described (Hendry and Iversen, 1971). Protein was measured in aliquots of neuronal extract by the bromosulfophthalein binding method of Wallace and Partlow (1978), using bovine serum albumin as a standard.

Metabolic labeling of neurotransmitters. Norepinephrine, dopamine, and $\mathrm{ACh}$ production were measured in living cells by scintillation counting of the electrophoretically separated metabolites of L-[ring $\left.2,6{ }^{3} \mathrm{H}\right]$ tyrosine $(30$ $\mathrm{Ci} / \mathrm{mmol} ; \mathrm{NEN})$ and $\left[\right.$ methyl $\left.-{ }^{3} \mathrm{H}\right]$ choline chloride $(80 \mathrm{Ci} /$ $\mathrm{mmol}$; NEN). Isotopic incubations and paper electrophoresis were carried out as described previously (Mains and Patterson, 1973). 
Immunocytochemical staining. Cultures were fixed with $4 \%$ paraformaldehyde in $0.12 \mathrm{M}$ phosphate buffer for $40 \mathrm{~min}$ at room temperature and rinsed three times with phosphate-buffered saline. They were then incubated for 30 min at $37^{\circ} \mathrm{C}$ with a rabbit antiserum generated against TH purified from rat pheochromocytoma (Thibeault et al., 1981), diluted 1:3000 in a high ionic strength buffer consisting of $0.5 \mathrm{M} \mathrm{NaCl}$ in $10 \mathrm{nM}$ phosphate buffer at $\mathrm{pH}$ 7.4 which contained $10 \%$ horse serum, $0.3 \%$ Triton X-100, and $0.1 \%$ sodium azide. The diluted antibody was incubated on ice for $1 \mathrm{hr}$ before use with horse serum. Primary antibody binding was visualized by the method of Sternberger (1979), using peroxidase-antiperoxidase (Boehringer-Mannheim) with a Hanker-Yates chromagen and cobalt intensification. The second antibody was sheep anti-rabbit serum. To facilitate comparisons, photographs were taken at the same exposure and printed under identical conditions.

\section{Results}

Three different culture conditions were used to control transmitter choice. The most cholinergic cultures were obtained by supplementing the medium with partially purified cholinergic inducing factor from serum-free medium conditioned by neonatal rat heart cells (Fukada, 1980). The resulting neuronal growth medium was concentrated 5 -fold for the conditioned medium factor (CM) compared to the original heart culture supernatants. On the other hand, the neurons can be maintained in their original noradrenergic state, and they are resistant to the effects of the cholinergic factor if they are depolarized by electrical stimulation, veratridine treatment, or elevation of external $\mathrm{K}^{+}$concentration (Walicke et al., 1977). The elevated $\mathrm{K}^{+}$method was used here. Cultures of intermediate transmitter status were grown in nondepolarizing medium and without CM.

Transmitter synthesis in living neurons was determined by metabolic labeling with $\left[{ }^{3} \mathrm{H}\right]$ tyrosine and $\left[{ }^{3} \mathrm{H}\right\rceil$ choline. In Figure 1, $a$ and $b$, are shown the content of metabolically labeled ACh and CA accumulated per neuron under each culture condition. As previously reported, the production of these transmitters is reciprocally related under conditions of strong cholinergic induction (Patterson and Chun, 1977a). CA production in cultures grown with CM is only one-fifth that of the most noradrenergic cultures, whereas ACh production is increased 20 -fold. In the intermediate condition examined here, $\mathrm{ACh}$ and $\mathrm{CA}$ are produced in similar amoutns.

$\mathrm{TH}$ activity was assayed in homogenates of sister cultures of those used for metabolic labeling. The specific activity of $\mathrm{TH}$ in extracts from cells grown under each culture condition in a representative experiment is shown in Figure 1c. TH activity is similar in extracts from cultures grown under noradrenergic conditions and from cultures of intermediate transmitter status. Activity in extracts from cholinergic cultures is about 5-fold lower. Thus, measurement of TH activity in extracts parallels that of CA synthesis and accumulation by metabolic labeling. This correspondence between the two measures of $\mathrm{CA}$ production has been observed in six separate platings. TH specific activity in extracts of cultures of intermediate transmitter status is comparable to that reported by Iacovitti et al. (1981) and Swerts et al. (1983) for dual function cultures.

To determine whether the cholinergic culture extract contained a $\mathrm{TH}$-inhibitory activity, a mixing experiment was performed. Equal amounts of extracts from cultures grown under adrenergic and cholinergic conditions were combined and assayed. The TH specific activity of this mixture was the average of the activities of the two contributing extracts (data not shown). No inhibitory activity of the cholinergic extract or enhancing activity of the noradrenergic extract was detected.

The presence of $\mathrm{TH}$ in cultures was also assessed by immunocytochemical staining using the peroxidase-antiperoxidase technique. Intense staining of neuronal somas and light staining of neuronal processes were seen in cultures grown under depolarizing conditions (Fig. 2a).
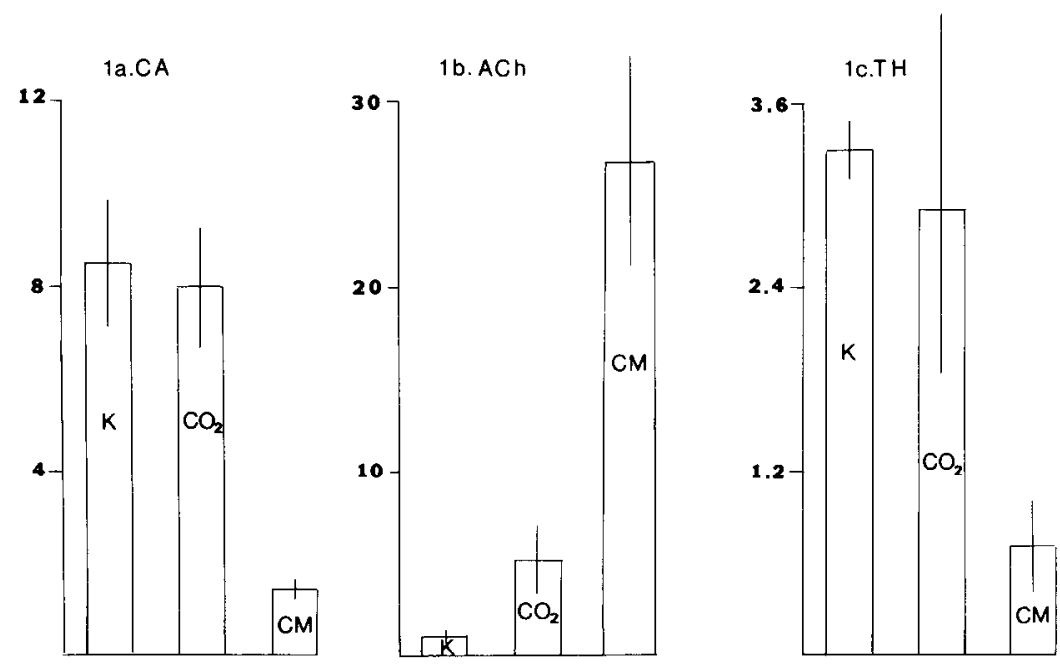

Figure 1. CA and $\mathrm{ACh}$ production, and TH activity in cultured sympathetic neurons. $a$, CA synthesis measured by metabolic labeling as described under "Materials and Methods," in femtomoles per neuron (mean \pm SD for three cultures). $b$, ACh synthesis measured by metabolic labeling as described in the text, in femtomoles per neuron (mean $\pm \mathrm{SD}$ for three cultures). $c$, TH activity in culture extracts assayed as described under "Materials and Methods," expressed as picomoles of DOPA per $\mu \mathrm{g}$ of protein per $10 \mathrm{~min}$ (mean and range of values for two different extracts, each containing three pooled cultures). $K$, cultures grown in high potassium; $C O$, cultures grown without depolarization or heart cell conditioned medium; $C M$, cultures grown with heart cell conditioned medium. 

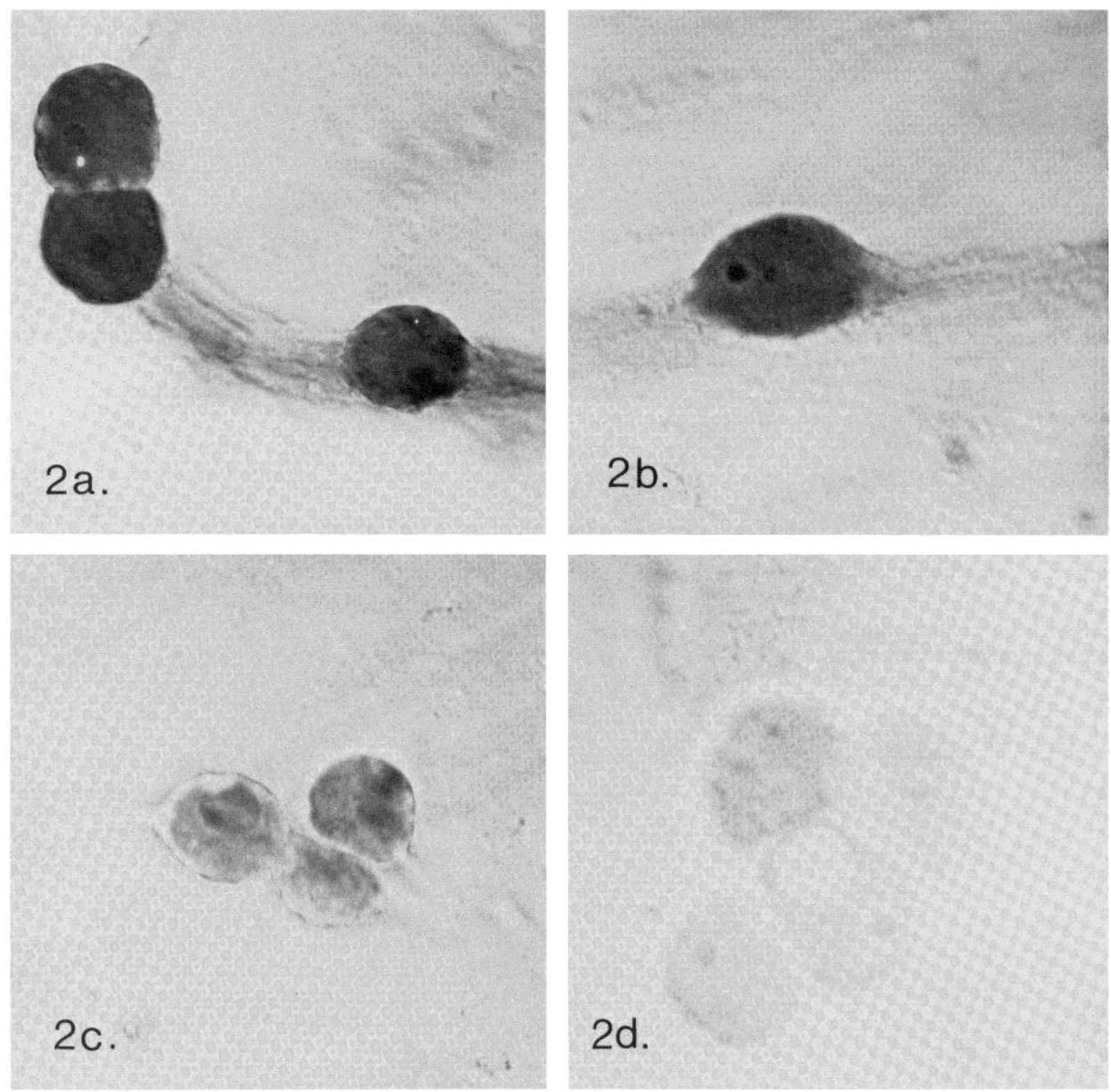

Figure 2. TH staining of cultured sympathetic neurons. $a$, Cells were grown in high potassium. $b$, Cells were grown without depolarization or heart cell conditioned medium. $c$, Cells were grown with heart cell conditioned medium. $d$, Cells were grown without depolarization or heart cell conditioned medium and were processed without primary antibody.

Somas of dual function neurons stained somewhat less darkly, and process staining was also less evident (Fig. $2 b$ ). Processes of neurons grown in CM were unstained, but their somas, though much lighter than those of the noradrenergic and dual function cultures, were significantly darker than the background obtained in the absence of primary antibody (Fig. 2, $c$ and $d$ ).

\section{Discussion}

The data reported here show that $\mathrm{TH}$ activity in extracts of cultured sympathetic neurons correlates well with levels of CA synthesis and accumulation measured by metabolic labeling of living cells. Furthermore, TH activity and immunocytochemical staining is inversely related to levels of $\mathrm{ACh}$ production in cultures subjected to a strong cholinergic induction. Metabolic labeling measures the combined results of transmitter synthesis, storage, release, reuptake, and degradation. Theoretically, a change in any one of these processes would change the net production of CA. It is also possible that rates of synthesis and degradation could change together in a compensatory manner, leaving final CA production levels unchanged. The observation that the activity of the rate-limiting enzyme of CA synthesis, $\mathrm{TH}$, parallels the metabolic labeling of CA suggests that this is the case, and that the processes affecting breakdown of CA are regulated in concert rather than separately. This is consistent with the linkage of the expression of other noradrenergic indicators such as endogenous CA stores (Johnson et al., 1976; Landis, 1980), the presence of the adrenergic form of monoamine oxidase (Pintar et al., 1981), certain spontaneously released (Sweadner, 1981) and surface membrane glycoproteins (Braun et al., 1981) 
and glycolipids (Zurn, 1983) enriched in noradrenergic neurons, and increases in certain lectin- (Schwab and Landis, 1981) and monoclonal antibody-binding sites (Chun et al., 1980). These markers of the noradrenergic state are good candidates for coordinate regulation. These noradrenergic traits are regulated reciprocally with cholinergic functions, but this is only apparent when a strong cholinergic induction is achieved. Thus it is possible that Iacovitti et al. (1981) did not observe early leveling off of $\mathrm{TH}$ activity because their cultures were not exposed to sufficient levels of cholinergic inducing factor.

Even in predominantly cholinergic cultures, decreased but still detectable amounts of CA are produced (Fig. $1 b$ ). Low levels of TH activity can also be detected in extracts of these cultures (Fig. 1c), and faint immunocytochemical staining for $\mathrm{TH}$ can be observed in fixed cultures (Fig. 2). The most straightforward interpretation of these findings is that TH is present in cholinergically induced neurons, but in lower amounts than in cells grown under noradrenergic conditions. The possibility that the amount of enzyme protein is the same in both types of extracts, but that its activity is modulated by an inhibitor or an activator, was tested by assaying mixed homogenates. No such effect was detected. The observation that the immunocytochemical staining results agree qualitatively with the activity data also argues against this possibility.

The failure of TH activity and immunocytochemical staining to fall to zero in even the most cholinergic cultures parallels the observation of faint immunocytochemical staining for $\mathrm{TH}$ and dopamine $\beta$-hydroxylase in mature cholinergic sympathetic fibers of the rat sweat gland (Siegel et al., 1982). In addition, the ability to take up exogenous CA persists after cholinergic development both in vivo (Landis and Keefe, 1980, 1983a) and in vitro (Landis, 1976; Reichardt and Patterson, 1977; Wakshull et al., 1978). The significance of these reduced but detectable noradrenergic characteristics in mature cholinergic sympathetic neurons is unknown. The ontogeny of sympathetic neurons involves a migration of neural crest cells along pathways which appear to exert an adrenergic influence on neuronal precursors (Le Douarin, 1980). Later in development, the small percentage of the population which becomes cholinergic does so by undergoing a phenotypic transition. This mechanism for producing cholinergic sympathetic neurons may result in traces of CA biosynthetic enzymes and uptake sites being present as vestiges of their developmental history. It is possible that an even stronger cholinergic induction would result in the complete disappearance of these traits, but complete obliteration of the noradrenergic phenotype is not necessary in vivo and is not yet attained in vitro. Another possibility is that complete loss of these markers does not occur because these functions are a necessary part of the final phenotype.

\section{References}

Bocchini, V., and P. U. Angeletti (1969) The nerve growth factor: Purification of a 30,000-molecular weight protein. Proc. Natl. Acad. Sci. U. S. A. 64: 787.

Braun, S. J., K. J. Sweadner, and P. H. Patterson (1981)
Neuronal cell surfaces: Distinctive glycoproteins of cultured adrenergic and cholinergic sympathetic neurons. J. Neurosci. 1: 1397-1406.

Chun, L. L. Y., P. H. Patterson, and H. Cantor (1980) Preliminary studies on the use of monoclonal antibodies as probes for sympathetic development. J. Exp. Biol. 89: 73-83.

Cochard, P., M. Goldstein, and I. B. Black (1978) Ontogenetic appearance and disappearance of tyrosine hydroxylase and catecholamines in the rat embryo. Proc. Natl. Acad. Sci. U. S. A. 75: 2986.

Cochard, P., M. Goldstein, and I. B. Black (1979) Initial development of the noradrenergic phenotype in autonomic neuroblasts of the rat embryo in vivo. Dev. Biol. 71: 100.

Fukada, K. (1980) Hormonal control of neurotransmitter choice in sympathetic neurone cultures. Nature 287: 553-555.

Furshpan, E. J., P. R. MacLeish, P. H. O'Lague, and D. D. Potter (1976) Chemical transmission between rat sympathetic neurons and cardiac myocytes developing in microcultures: Evidence for cholinergic, adrenergic, and dual-function neurons. Proc. Natl. Acad. Sci. U. S. A. 73: 4225-4229.

Hawrot, E., and P. H. Patterson (1979) Long term culture of dissociated sympathetic neurons. Methods Enzymol. 58: 574584.

Hendry, I. A., and L. L. Iversen (1971) Effect of nerve growth factor and its antiserum on tyrosine hydroxylase activity in mouse superior cervical sympathetic ganglion. Brain Res. 29: 159-162.

Higgins, D., L. Iacovitti, T. H. Joh, and H. Burton (1981) The immunocytochemical localization of tyrosine hydroxylase within rat sympathetic neurons that release acetylcholine in culture. J. Neurosci. 1: 126-131.

Iacovitti, L., T. H. Joh, D. H. Park, and R. P. Bunge (1981) Dual expression of neurotransmitter synthesis in cultured autonomic neurons. J. Neurosci. 1: 685-690.

Johnson, M., D. Ross, M. Myers, R. Rees, R. Bunge, E. Wakshull, and H. Burton (1976) Synaptic vesicle cytochemistry changes when cultured sympathetic neurons develop cholinergic interactions. Nature 262: 308-310.

Johnson, M., C. D. Ross, M. Myers, S. L. Spitznagel, and R. P. Bunge (1980) Morphological and biochemical studies on the development of cholinergic properties in cultured sympathetic neurons. I. Correlative changes in choline acetyltransferase and synaptic vesicle cytochemistry. J. Cell Biol. 84 : 680-691.

Johnson, M. I., and D. Higgins (1981) Predominantly clear vesicles of cholinergic sympathetic neurons in culture become dense-cored following depolarization and reloading with norepinephrine: Preliminary observations. Soc. Neurosci. Abstr. 7: 847.

Landis, S. C. (1976) Rat sympathetic neurons and cardiac myocytes developing in microcultures: Correlation of the fine structure of endings with neurotransmitter function in single neurons. Proc. Natl. Acad. Sci. U. S. A. 73: 4220-4224.

Landis, S. C. (1980) Developmental changes in the neurotransmitter properties of dissociated sympathetic neurons: A cytochemical study of the effects of medium. Dev. Biol. 77 : 349-361.

Landis, S. C., and D. Keefe (1980) Development of cholinergic sympathetic innervation of eccrine sweat glands in rat footpad. Soc. Neurosci. Abstr. 6: 379.

Landis, S. C., and D. Keefe (1983a) Evidence for neurotransmitter plasticity in vivo I. Catecholamine uptake by cholinergic sympathetic neurons of adult rats. Dev. Biol., in press.

Landis, S. C., and D. Keefe (1983b) Evidence for neurotransmitter plasticity in vivo II. Presence of catecholamine in cholinergic sympathetic neurons of developing rats. Dev. Biol., in press.

Le Dourain, N. M. (1980) The ontogeny of the neural crest in avian embryo chimaeras. Nature 286: 663-669. 
Mains, R. E., and P. H. Patterson (1973) Primary cultures of dissociated sympathetic neurons. I. Establishment of longterm growth in culture and studies of differentiated properties. J. Cell Biol. 59: 329-345.

Patterson, P. H., and L. L. Y. Chun (1977a) The induction of acetylcholine synthesis in primary cultures of dissociated rat sympathetic neurons. II. Developmental aspects. Dev. Biol. 60: 473-481.

Patterson, P. H., and L. L. Y. Chun (1977b) The induction of acetylcholine synthesis in primary cultures of dissociated rat sympathetic neurons. I. Effects of conditioned medium. Dev. Biol. 56: 263-280.

Patterson, P. H., L. F. Reichardt, and L. L. Y. Chun (1975) Biochemical studies on the development of primary sympathetic neurons in cell cultures. Cold Spring Harbor Symp. Quant. Biol. 40: 389-398.

Pintar, J. E., G. D. Maxwell, K. J. Sweadner, P. H. Patterson, and X. O. Breakefield (1981) Monoamine oxidase activity in early quail embryos and rat neuron cultures with different transmitter phenotypes. Soc. Neurosci. Abstr. 7: 848.

Potter, D. D., S. C. Landis, and E. J. Furshpan (1981) Adrenergic-cholinergic dual-function in cultured sympathetic neurons of the rat. Ciba Found. Symp. 83: 123-138.

Reichardt, L. F., and P. H. Patterson (1977) Neurotransmitter synthesis and uptake by isolated sympathetic neurons in culture. Nature 270: 147-151.

Schaffner, A. E., and M. P. Daniels (1982) Conditioned medium from cultures of embryonic neurons contains a high molecular weight factor which induces acetylcholine receptor aggregation on cultured myotubes. J. Neurosci. 2: 623-632.

Schwab, M., and S. C. Landis (1981) Membrane properties of cultured rat sympathetic neurons: Morphological studies of adrenergic and cholinergic differentiation. Dev. Biol. 84: 6778.

Siegel, R., M. Schwab, and S. C. Landis (1982) Developmental changes in the neurotransmitter properties of cholinergic sympathetic neurons in vivo. Soc. Neurosci. Abstr. 8:7.
Sternberger, L. A. (1979) Immunohistochemistry, Ed. 2, John Wiley \& Sons, Inc., New York.

Sweadner, K. J. (1981) Environmentally regulated expression of soluble extracellular proteins of sympathetic neurons. J. Biol. Chem. 256: 4063-4070.

Swerts, J. -P., A. Le Van Thai, and M. J. Weber (1983) Tyrosine hydroxylase, dopa decarboxylase and dopamine $\beta$-hydroxylase are all depressed in cultured rat sympathetic neurons undergoing a switch from adrenergic to cholinergic phenotype. Dev. Biol., in press.

Teitelman, G., H. Baker, T. H. Joh, and D. J. Reis (1979) Appearance of catecholamine-synthesizing enzymes during development of rat sympathetic nervous system: Possible role of tissue environment. Proc. Natl. Acad. Sci. U. S. A. 76: 509-513.

Thibeault, J., D. Vidal, and F. Gros (1981) In vitro translation of mRNA from rat pheochromocytoma tumors, characterization of tyrosine hydroxylase. Biochem. Biophys. Res. Commun. 99: 960-968.

Wakshull, E., M. J. Johnson, and H. Burton (1978) Persistence of an amine uptake system in cultured rat sympathetic neurons which use acetylcholine as their transmitter. J. Cell Biol. 79: 121-131.

Walicke, P. A., R. B. Campenot, and P. H. Patterson (1977) Determination of transmitter function by neuronal activity. Proc. Natl. Acad. Sci. U. S. A. 74: 3767-3771.

Wallace, L. H., and L. M. Partlow (1978) A sensitive microassay for protein in cells cultured on collagen. Anal. Biochem. 87: $1-10$.

Weber, M. J. (1981) A diffusible factor responsible for the determination of cholinergic functions in cultured sympathetic neurons: Partial purification and characterization. J. Biol. Chem. 256: 3447-3453.

Zurn, A. D. (1983) Identification of glycolipid binding sites for soybean agglutinin and differences in the surface glycolipids of cultured adrenergic and cholinergic sympathetic neurons. Dev. Biol. 94: 483-498. 